\title{
Groupwork and Assessment
}

Rob Watkins, Kingston University

1 Introduction

$2 \quad$ Why use group work?

2.1 How group work can improve learning outcomes

2.2 How group work can assist with practical issues facing lecturing staff 4

3 How can we make group work effective? 5

3.1 Motivation 5

$\begin{array}{lll}3.2 & \text { Designing group work } & 7\end{array}$

4 Assessment 16

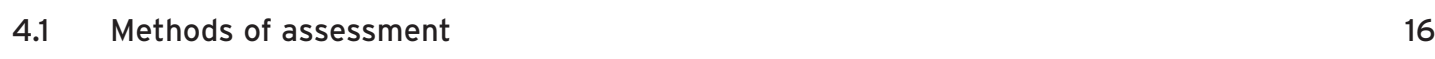

$\begin{array}{lll}4.2 & \text { Peer- and self-assessment } & 16\end{array}$

$\begin{array}{ll}4.3 & \text { Allocating marks in group assessments } \\ \end{array}$

5 Where next? 19

$\begin{array}{lll}5.1 & \text { Group structure } & 19\end{array}$

$\begin{array}{llr}5.2 & \text { Feedback } & 19\end{array}$

$\begin{array}{lll}5.3 & \text { Reflective logs } & 19\end{array}$

$\begin{array}{lll}5.4 & \text { Assessment } & 19\end{array}$

$\begin{array}{ll}5.5 & \text { Group selection } \\ & 19\end{array}$

5.6 Virtual Learning Environments 20

$\begin{array}{lll}5.7 & \text { Economics test questions applicable for group work } & 20\end{array}$

$\begin{array}{lll}5.8 & \text { General } & 20\end{array}$

$\begin{array}{ll}\text { References } & 21\end{array}$ 


\section{Introduction}

Course delivery by 'chalk and talk' is still the predominant process favoured by economics university departments, but with an estimated 75 per cent of departments using group projects and presentations it seems that group work can already be designated as significant (Economics LTSN, 2003). An increasing interest in group work has been promoted by higher student-lecturer ratios and rhetoric about learning and teaching.

This chapter on the 'why', 'how' and 'what' of economics group work in higher education is ambitious. It attempts to give relevant justification, explanation and ideas to those who are considering group work options for the first time, while providing details to a conceptual and practical standard that are of use to the more seasoned exponent.

Section 2 addresses some practical issues in using group work, at the same time as exploring potential benefits in terms of learning outcomes. Lecturers who have been hesitant to reduce their reliance on traditional teaching methods may find this particularly useful.

Section 3 acknowledges the critical part that motivation has to play in the success or failure of groups. This section offers some practical measures that aim to improve the effectiveness of group work by achieving high levels of student motivation.

In designing group work, the lecturer selects from so many options that the final design will almost certainly be unique. Whilst accepting this, section 3 offers a tentative template for group work. It aims to:

- identify the key issues to be considered in designing group work;

- analyse the implications of the design of group tasks;

- evaluate the options for assessment. 


\section{Why use group work?}

\subsection{How group work can improve learning outcomes}

\section{Deep learning}

Group work can help students to become more active in their learning (Ruel and Bastiaans, 2003). When working with peers in a group, students are encouraged to articulate their ideas and question the ideas of others. When it works, this leads to a social process of constructing ideas and developing possible solutions to problems. Hendry et al. (1999) describe the link between constructivism philosophy and problem-based learning. This active engagement with peers in learning should be more likely to lead to 'deep learning', in which students really understand the meaning of theories.

\section{Employability}

Economics students can expect to spend a large part of their careers working in groups, whether in committees or project teams. Employers need good team workers and better social skills will increase students' employability. A recent survey of employers in Wales found that team and group working skills were ranked fourth in importance after communication, understanding customer needs and the ability to learn (Cardiff University, 2001). Group work activity in higher education provides practice in the salient skills and the opportunity to refer to this experience.

\section{QAA benchmarks}

Group work can help to meet the QAA criteria for economics (QAA, 2000). These criteria refer to the importance of providing 'active and deep learning opportunities' for students' learning, and group work is one way of delivering these opportunities. Group work can also contribute to the achievement of various aims of the economics degree programme, such as:

- to develop the ability to apply knowledge and skills;

- to develop, through the study of economics, a range of transferable skills to be of value in employment;

- to develop relevant skills for constructive use of that knowledge in a range of settings;

- to stimulate students intellectually, leading them to apply economics to a range of problems in a variety of contexts. (See QAA $(2000$, p. 1) for a list of the main aims of an economics degree programme).

\section{Variety is the spice}

It is often argued that students prefer different styles of learning (Charkins et al., 1985; Lage et al., 2000). For example, the Grasha-Reichmann questionnaire for categorising learning styles uses a student classification of dependent learners, collaborative learners and independent learners. The implication is that students who are collaborative learners benefit substantially 
when learning in a group process and that teaching should give opportunities for each type of student to learn in the style they prefer. This means providing a mix of opportunities to learn, including working in groups. 'Instructors who use only the dependent teaching style can improve economic understanding and attitudes toward economics by utilising other teaching methods' (Charkins et al., 1985, p. 112). Whilst these arguments have gained considerable influence in some quarters, a recent review of the evidence for such categorisations (Coffield et al., 2004) is broadly sceptical of the claims made for learning styles inventories.

\subsection{How group work can assist with practical issues facing lecturing staff}

\section{Massification}

Many higher education establishments have experienced large increases in student numbers and this can support the rationale for introducing more group work. First, it might be regarded as a palliative for the resource problems that massification tends to create. Second, it may be championed as a practicable way of providing good learning experiences for students.

Increases in student numbers typically reduce the average lecturer time available for each student and certain forms of group work can be offered as a partial solution. Class contact time can be reduced if students are asked to work in groups outside of the direct supervision of lecturing staff. Individual projects can be replaced by group projects. However, group work can take many hours of administration to make sure that the process runs smoothly.

Massification also puts pressure on the quality of teaching. How do lecturers engage the feelings and emotions of a large body of students, whom they neither meet individually nor know by name? If the cited benefits of group work can be realised, the productivity of teaching might be raised through improvements in quality as well as through reductions in resources per head. For example, following Kolb's (1984) model of experiential learning, students might be more effectively engaged in their learning, develop their initiative and motivation, and show increased commitment in their learning.

\section{Developing students' skills}

It is now usual for undergraduate awards to be required to include in their aims a commitment to developing students' skills. Statements are easily written into award documents, but less easily located in the experiences that are provided for students or the outcomes that are assessed. Group work projects provide practicable opportunities for the application of transferable skills (such as teamwork, leadership, communication and project management) and these opportunities are easy to write into module specifications. Identifying students' progress in these skills is more of a challenge and one that lies beyond the scope of this chapter.

\section{Source of social identity}

For students studying within a mass education environment there can be social and personal benefits of being allocated into relatively small, clearly identified, task-oriented groups. There is a longstanding body of research suggesting that membership of groups can make a major contribution to an individual's sense of identity and self-evaluation (see, for example, Festinger, 1954). 


\section{How can we make group work effective?}

This section is intended to be useful when you are considering the design of a group work project and wish to check it against concepts of what motivates and demotivates students.

\subsection{Motivation}

Motivation is such an important element in student group work that it deserves specific attention. For example, Morgan (2002) reported that almost half the perceived problems of group work could be allocated to the 'poor motivation - general category'. We can identify types of motivation loss and concepts of students' motivation that should facilitate better design of task and process.

\section{Initial motivation}

A practical, generic strategy is to ensure that from the start the students' perceptions of what is required are realistic. Students should be given a breakdown of the marking standards that are applied to the group work and a clear explanation of performance expectations. Skok (2003) offers an example of an analogy presented to students to illustrate their various performance and standards options, together with a description of general marking standards that are given out to students at Kingston Business School.

\section{Social loafing}

Social loafing is a reduction in individual effort because of the presence of other people and is most likely to occur when students feel less likely to be identified. As such it is primarily task related. Tasks need to be designed so that students' contributions are more likely to be noticed. For example, divisible tasks will counter this problem more easily than unitary tasks. (In a divisible task, each student produces the answer to one question, while a unitary task could be a group decision on the appropriate answer.) This can also be related to size of groups, as the larger the group is, the less likely your reduced effort is to be noticed.

\section{Free riding}

While social loafing relates to not being noticed, free riding is the opportunity to get something for nothing. The group task is not seemingly affected by the student's reduced performance and/or the student does not suffer any penalty for this minimised effort. Can the group task be designed so that there are penalties for reduced involvement, and possibly rewards for above average participation? Students may be asked to rate the contribution that others have made to the group effort. Free riding and non-performance might be infringing certain norms or social rules - norms such as reciprocity and equity, where the ratios of effort to marks received should be fair between group members. 


\section{Inequity based motivation loss}

If students see that a member of the group is free riding, they might try to avoid the 'sucker effect' by reducing their own input. This concept can be developed further by reference to the 'means rule'. Students are less likely to think of themselves as 'suckers' if they are covering for a member of the group who is not able to succeed. When assessing fairness with regard to inputs (effort) and outputs (marks), they take into account the abilities of their fellow students. It may be useful if the process is structured so that students get to know each other better. If students are able to make more accurate judgements about the abilities of fellow group members, this may reduce the free-rider 'sucker' effect.

\section{Social dilemma}

Students sometimes have the social dilemma of making a choice between behaviour that maximises their private benefit and behaviour that maximises social benefit to the group. For example, by attending all meetings or reading and responding to the minutes, students are giving up their own time. They are assisting in group activity, an action that could be classified as 'cooperation'. Alternatively, they could do the minimum necessary and keep most of the time for their own preferred activities. This action could be classified as 'defection'. If all group members choose 'defection' the total outcome will be inferior to the outcome where all group members choose 'co-operation'.

This is a classic game theory problem that could be addressed by increasing the pay-off when all members of a group choose a co-operative strategy. The Prisoner's Dilemma suggests that the imposition of a many-stage game, with its facility for a tit-for-tat strategy directs the selfinterested player to adopt a co-operative approach rather than maximise his or her initial selfinterest. A group task that is broken down into a number of stages could increase the likelihood of mutually beneficial behaviour and a better-performed task.

\section{Motivations beyond Homo economicus - intrinsic motivation}

Besides the motivational assumption about maximising our own self-interest, there are implications from the ideas about non-welfare-maximising motivations. Some concepts, such as sympathy, can be rationalised into self-interest models through the idea that by helping others we are making ourselves feel better. However, commitment-based behaviour, such as honesty and altruism, is demonstrably a different source of motivation. Some authors refer to the equivalent concepts of calculating and non-calculating motivations. Homo economicus will act in his or her own best interest in response to external incentives such as marks, while intrinsic motivation refers to examples such as:

- regard for others - we may do certain activities because we enjoy working as a team and value our relationship with others;

- desire to impress others, showing skill or pride;

- ethical values;

- acting in order to establish a form of identity, the action being a reflection of how we see ourselves;

- desire to fit in with the norms and social structures of the community.

These sources of motivation are more likely to be present when students have a long-term commitment to a group. 


\subsection{Designing group work}

This subsection is intended to provide a checklist and assessment of some of the most important elements in the design of group work. Lecturers may find it helpful as a prompt or reference when considering their own group design.

\section{Initial expectations}

At the start of the module, students bring or quickly develop a set of expectations. It can be helpful to consider what elements can be manipulated to increase the probability of more effective group work. Expectations are influenced by word of mouth from previous students, so to some degree the expectations are a function of the previous years' operations. As an 'intangible service', perceptions about the level of the course and by association the level of their required contribution are additionally influenced by the introductory materials that students encounter. Care should be taken over presentation details to give impressions of professionalism, clarity and academic rigour.

\section{Helping students to understand the arguments for using group work}

It can be helpful to explain to students the benefits of using group work. Although this takes time out from discussing economic theory, it can help to motivate students to make much better use of the opportunities that are provided through group work. For example, the lecturer might emphasise the 'deep learning' and employability benefits described in section 2.1.

\section{Role of lecturer}

The role of the economics lecturer or tutor for group work activity will typically move from a formal provider of knowledge to a more supportive role. With proactive interference in the group's direction and learning processes, and because of his or her greater subject and group work experience, the economics tutor is well placed to facilitate the group's progress. However, tutors need to consider whether the benefits gained from interference to ensure positive outcomes outweigh the disadvantages of reduced group autonomy. For identification of dangers that can occur with tutor interference and practical suggestions for limiting the damage, see the chapter on 'Group facilitator behaviours that can damage group work' (Race, 2000, pp. 99-109).

Ruel and Bastiaans (2003, p. 28) provide a more fine-grained classification of different roles that the tutor may take on. They distinguish between:

- close involvement in the processes of the group;

- showing links and explaining concepts;

- giving initiative space to the group;

- providing the stimulation for development.

We can generalise that one form of good practice is a comprehensive set of published operational procedures. If they lay out the boundaries and roles for group activity, it may prompt students towards greater participation and engagement, in contrast to their original expectations of a tutor-led process. This point about the advantages of comprehensive content can be added to the earlier point about clarity and professionalism of presentation in order to influence initial expectations favourably. 


\section{Types of task}

When assessing whether a group task is fit for the purpose intended, it can be helpful to consider categories such a: disjunctive, conjunctive, additive and discretionary (Steiner, 1972).

- Disjunctive tasks are those that only need one group member to be capable of achieving the task. This can be a useful method of spreading the correct answer around the student body, but it does not oblige group members to think, as they can rely on the most knowledgeable member of the group.

- Conjunctive tasks are those where each group member has to contribute. If these are successfully completed, we could expect more group learning to take place, but the requirement for full participation increases the chances of group failure.

- Additive tasks refer to group work where each additional group member can add something to the output.

- Discretionary tasks are so called because group members have discretion in how they combine their efforts.

To illustrate these concepts by group tasks, we can reference some of the cooperative learning exercises in Robin Bartlett's chapter in Becker and Watts (1998, pp. 18-29):

- 'Counting Triangles' in a diagram. This could be a disjunctive task for the group, as only one member needs to calculate it correctly. However, by adding the requirement that any member of the team may be selected at random to explain their answer, it acquires more of the characteristics of a conjunctive task.

- A 'Cooperative Writing' exercise. This describes what might be categorised as an additive task. Bartlett outlines this in practical detail. A typical example could be:

1. A group is given a topic that is being covered on the course (e.g. 'Should the UK adopt the euro?')

2. The group is asked to divide this topic into sub-components.

3. If there are five group members, there will be five sub-components (for example, the Chancellor's five economic tests: business cycles compatible and sustainable; flexibility to deal with problems; effect on long-term investment; effect on financial services industry; effect on growth, stability and employment).

4. Each member is given one of these subjects and asked to write on it for 10 minutes.

5. They then pass their work to a colleague for comments, alterations and suggestions (say, 5 minutes).

6. Then each of the five scripts is passed to another colleague for further comments and alterations ( 5 minutes) This process continues until all students have seen and commented on all five scripts.

7. One group member is then allocated (randomly or voluntarily) to take all five scripts and write up the final draft, possibly to be submitted the next day.

- 'Jigsaw'. This is an exercise where each group has a different piece of economic data and to analyse the issue they need to understand the information held by the other groups. For example, a group may be asked to evaluate macroeconomic forecasts or policy decisions. Groups can be given separate economic figures for elements such as inflation, unemployment and money supply, but they will need analysis of the other groups' data before they can make confident predictions or policy suggestions. The exercise involves the group analysing their 
own set of data to reach conclusions; discussing and presenting their conclusions with other groups; analysing or critiquing the other groups' conclusions. How the individual works and combines with others in his or her group appears to be a matter of discretion and 'Jigsaw' might accordingly be classified as a discretionary task.

Most experiments and simulation exercises are natural vehicles for group work. The activities are frequently designed to help students to understand the dynamics of economic interactions within and between groups. For example, Lage et al. (2000, p. 33) describe a production exercise in which additions to groups are used to illustrate marginal concepts in production.

\section{Group size}

Group size is a widely considered variable in group design, as it affects outcomes in terms of performance and practicability. The most appropriate size of group may be a function of the task. In a disjunctive task, if one member of the group can do the task, the whole group can get the right answer. This would be the case if the task were to identify the right answer in a multiple-choice test. In this case, the probability of the group containing someone capable of doing the disjunctive task will increase with group size.

According to Steiner $(1972)$, the formula $100\left(1-Q^{n}\right)$ gives the probability that at least one person in the group can perform the task. $Q$ refers to the proportion of the population who cannot do the task, while $n$ refers to the number of students in the group. For example, as shown in Table 1, Steiner calculates that if we estimate that only 40 per cent of a cohort of students could successfully complete a task and we have groups of five, there is a 92 per cent probability of each group containing someone who can complete the task. Of course, this assumes that students are randomly allocated across groups and this condition will be violated if students select the group composition themselves.

\begin{tabular}{|c|c|c|c|c|c|}
\hline $\begin{array}{c}\text { Size of } \\
\text { group }\end{array}$ & $10 \%$ & $20 \%$ & $40 \%$ & $60 \%$ & $100 \%$ \\
\hline 2 & 19 & 36 & 64 & 84 & 100 \\
5 & 42 & 67 & 92 & 99 & 100 \\
10 & 65 & 89 & 99 & 100 & 100 \\
20 & 88 & 99 & 100 & 100 & 100 \\
\hline
\end{tabular}

Table 1. Steiner's calculation of the probabilities of a group containing an individual who can complete a task

Conjunctive tasks are more demanding, in that each student in the group must be able to complete a particular activity. The group will move at the pace of the slowest member and the probability of the conjunctive task being successfully completed will accordingly decrease with larger groups.

Table 2 (page 10) presents a calculation of the probability of success in a conjunctive group task. In this table, $P$ is the percentage of the class population that has the ability to do the task and $n$ is the size of the group. The probability that the group can perform the task - that is, that all members of the group can perform the task - is $100\left(P^{n}\right)$. 


\begin{tabular}{c|c|c|c|c|c|}
\hline $\begin{array}{c}\text { Size of } \\
\text { group }\end{array}$ & \multicolumn{5}{|c|}{ Percentage who can do the task } \\
\hline 2 & $10 \%$ & $\mathbf{2 0} \%$ & $\mathbf{4 0 \%}$ & $\mathbf{6 0 \%}$ & $100 \%$ \\
5 & 1 & 4 & 16 & 36 & 100 \\
10 & 0 & 0 & 1 & 8 & 100 \\
20 & 0 & 0 & 0 & 1 & 100 \\
\hline
\end{tabular}

Table 2. The probability of a group being capable of performing a conjunctive task, according to Steiner's theory

A comparison between the two tables illustrates how much more likely a group of any size is to be successful, in terms of task completion, when it pursues a disjunctive rather than conjunctive task.

For example, let us assume we have a group of five students, that we ask the group to explain the Lucas price-surprise model and that we calculate that $60 \%$ of our class can answer the question.

- As it stands, this is a disjunctive task. Only one person in the group needs to know how to explain the answer. We accordingly calculate the probability of getting the right answer from the group as $100\left(1-0.4^{5}\right)$ : that is, 99 per cent.

- If we ask each student in the group to be able to explain the answer, we have a conjunctive task and the probability of getting this answer from all the group is $100\left(0.6^{5}\right)$ : that is, 8 per cent.

See Bligh (2000, pp. 129-30) for more comprehensive tables on the probabilities according to Steiner's theory.

Additive tasks refer to projects where each member's contribution 'adds' to the submission. The larger the group, the more contributions, and so we would expect larger groups to produce more. However, the group's output will be subject to the law of diminishing returns and at some point, depending on the task and process employed, additional students in the group will result in successively smaller additions to the group's total output.

We see that the output or probability of success of task (conjunctive, disjunctive or additive) is influenced by group size. A study of 50 economic groups ranging from 8 to 18 members, which considered such variables as size and their link with group marks, is provided by Watkins and Daly (2003).

In relation to the process, we can generalise that in larger groups the majority of individuals will learn less. This is supported by the concept that learning is assisted by participation and there is less of this participation in the larger group. The findings of Bales and Borgatta (1955) with regard to the effects of group size on the distribution of participation in a task-oriented group are seminal in this respect. They found that as group size increased, the variations in participation also increased.

We can generalise that smaller groups have process advantages over larger ones in terms of greater cohesion, less tension and increased motivation to co-operate. There should be less behaviour geared solely to satisfying personal requirements and the group members may be more constrained by group norms in the smaller group. The larger the group, the easier it is to hide and possibly the less likely students are to be equitably evaluated. Generally, smaller groups could be expected to mitigate motivation loss in the form of social loafing and free riding. 
So is there an optimal group size? With regard to quality of output we need reference to specific task, process and structure (see section 5 for further reading). With regard to the learning process, it is easier to be intuitive about the benefits of smaller groups. A number of current authors (for example, Cooper et al., 1990; Johnson et al., 1998) support group sizes of four to five students as they believe that larger groups restrict members' participation and so provide less opportunities for them to increase their skills. A summary of the implications of group size is presented in Box 1.

\section{Box 1 A Summary of the effects of group size}

- Pairs. Advantages include ease of arranging meetings and less likelihood of free riding.

- Couples. These are likely to put more effort into group work than random pairs.

- Threes. The likelihood of free riding is quite low, but there is a danger that one of the three may feel marginalised at some stage.

- Fours. Passenger behaviour is still less probable than in larger groups and the group can subdivide into twos.

- Fives. The possibility of free riding increases significantly. The role of the leader becomes more important.

- Sixes. The group can subdivide into twos or threes and so reduce the increased risk of passenger behaviour.

- Greater than sixes. The role of leader needs to change in order to get the group working together. There is a greater possibility of free riding. (Race, 2000, chapter 11)

\section{TOP \\ TIPS}

Here are some tips for working with larger groups:

- To maximise leadership effectiveness, consider introducing a split between task-and person-oriented leadership roles.

- With a large number of students it is likely that there will be more conflicts. To assist group cohesion, consider devoting more time to group maintenance processes.

- For reasons of communication, friendship and manageability, large groups are more likely to subdivide into smaller working units. Consider designing the work so that it can be split into subgroups. Workshops with 20-30 students can be very practical in that they can be broken up into subgroups for plenary sessions, so giving students experience in both small and large groups.

- Larger groups may need a more formal structure and allocation of roles in order to ensure greater participation. The economics tutor may need to intervene more directly to introduce and support the formal structures.

- In the context of group performance, designing for larger groups may be more efficient as long as they can exploit the advantages of division of labour.

- If the task is designed as being too simple, a larger group cannot be expected to improve on the performance of a smaller group.

- If we have variable-sized groups, we need to take care over equitable marking for tasks involving random error. A combination of estimates within a larger group is statistically more likely to be accurate. 


\section{Providing feedback}

Feedback is a vital component in developing our own identity, reducing anxiety and driving learning (see section 5.2 for further reading). For information on feedback's relationship with self-image, confidence and esteem, see Bligh (2000, pp. 109-11). When group work is applied in experiments and games, the feedback from their assessment can highlight valuable economic lessons. An international trade game by Sloman (2002) outlines an activity suitable for a number of teams, providing insights into a variety of diverse macro and micro factors. A particularly notable feature of his work, in the context of this section, is the emphasis he places on debriefing students and determining the learning outcomes that this debriefing will facilitate.

Group work entails specific considerations in relation to feedback:

- In some circumstances, students may need individual communication due to the social position and the individual receiver's vulnerability when providing feedback within a group.

- When there are a large number of groups presenting reports on their discussion, it can be very boring for students to listen to each group's presentation. In these circumstances, they are likely to pay minimal attention and the tutor needs to design a process to deal with this. For example, the tutor could observe the groups' discussions and give a summary, and then ask the class for any additional points. Alternatively, he or she could ask each group for one point only. This reduces the difficulty for groups that report towards the end of the process. The class is then asked for any additional points at the end.

- Feedback is particularly valuable when received from our peers. Opportunities provided by group practices such as buzz groups should be utilised whenever possible.

Ideally, economics is a way of thinking about the world, providing insights into the way it operates and training students to think analytically. Many of the constituent parts of an economics course are greatly assisted by 'formative feedback', as students discuss positive concepts within the group.

\section{Flexibility}

If the dynamics of the group are poor, there should be flexibility to change various elements of an activity to make it into a more successful learning experience. Where students have been allocated to groups, they might be given the option of change. In the group work component of a first-year economics skills module at Kingston University, groups that are slow to combine effectively are offered the option of being divided into autonomous subgroups. Advantages of such flexibility may include greater commitment from group members because they can be involved in the change and possibly more appropriate groupings. The costs of flexibility can include the extra resources required to implement and monitor, the generation of uncertainty and a lengthening of lead times before the group 'beds down'.

\section{Increased co-operation}

Increased co-operation within a group appears to be generally beneficial. Apparently obvious but still worth pointing out is that members should be motivated by task and process design to co-operate with each other. This would occur when there is a positive interdependence of fate: that is, where one person's success directly helps or is necessary for others to succeed, as happens with teams. Johnson et al. (1981) reviewed 109 studies comparing co-operative with competitive structures for group work and found co-operative to be overwhelmingly superior.

The arguments in favour of increased co-operation include the following: 
- It may reduce 'transaction costs' and hence increase efficiency, as we need a less formalised system or reduced levels of monitoring.

- With goodwill and inter-group co-operation, the externalities that are experienced with group work can be better accommodated.

- With greater co-operation we are more likely to get an equitable allocation of rewards for group members.

- Co-operation is a useful method for reducing the risks and uncertainties that individual students will face.

The prevalence of virtual learning environments (VLEs) for economics lecturers has risen from 35 per cent in 2001 to 57.6 per cent in 2003 (Economics LTSN, 2003). They can add structure and a wide variety of group process support functions as well as having a number of beneficial effects on the format of participation (see section 5.6 for further reading). Developments in VLEs and appreciation of their potential appear to be positive drivers towards increased intergroup co-operation.

\section{Inter-group competition}

Studies generally indicate that, the greater the conflict between groups, the more cohesion there is within a group. This appears to be a phenomenon utilised by schools for many years with variations on their house systems. In addition to the process, the results of this inter-group competition may have an effect. When the outcome is in favour of the group, cohesion tends to increase, whilst if the group appears to be losing, there will be a force against group cohesion: that is, success raises and failure lowers morale.

\section{Group significance}

A practical finding by Holt (1987) was that that people will show decreased motivation in groups when the groups are psychologically insignificant. The implication is that if groups can be made to matter to their members, they are likely to commit more to the group effort. Can we make our groups matter more by preparing for seminars as thoroughly as for lectures, by increasing the 'fun' element, by providing activities that increase relevant interaction? Introductory discussions and social or physical exercises can all help increase group cohesion. Simple devices like giving groups names or identities can help in the process of making them more significant, and one of the suggestions by Bartlett (1998) is that colours are used to identify teams. This is on the basis that it helps build rapport and 'building team identity is important for building team cohesiveness'.

\section{Group selection}

Group composition can have major implications for the way and extent to which group work develops (see section 5.5 for further reading). There are two main alternatives to the allocation of students on the basis of practicability (typically, the timetable). Either the tutor selects groups on the basis of some preconceived criteria or the groups self-select.

A logical approach is to divide students between groups, so that their personal characteristics blend to produce a supportive and successful group. An example might be to identify students with high and low characteristics of attributes such as 'confidence', 'ability', 'motivation' and 'knowledge'. They could be allocated between groups with the intention that students with more of a characteristic can help or favourably influence the students with less of that characteristic.

Within the considerable amount of research into the variety of group roles needed to make a group successful, Belbin (1981) is worth highlighting as one of the most influential thinkers on 
relevant roles and the choice of appropriate individual characteristics. Eight clusters of behaviour are identified as relevant to team roles. See Gibbs (1994, p. 4) for a useful table of team roles, based on Belbin, which you could use in your team work. These roles are innovator, investigator, chairperson, shaper, evaluator, team worker, organiser and finisher.

A large amount of economic group work comprises short bursts of activity within seminars conducted on a weekly basis. In these circumstances, tutors will typically select groups on the basis of student proximity. It is interesting to note the observation by Johnston et al. (2000) when employing this method that, as the semester progressed, students began to sit nearest to the people with whom they felt comfortable working.

There is considerable argument for self-selection in terms of greater cohesion. By making their own group choice, students are more likely to feel greater levels of group identification. The author's experience is that where groups have been formed by tutor selection, the argument for self-selection is one of the most common features identified by students as a way to improve the course. One possible format (Moore, 1998) with self-selection is to adopt a very open approach to group formation:

- In the second week of the course, it is announced that students are free to form their own groups.

- Groups must consist of three or four students.

- Students could opt to be placed in groups on the basis of their timetable compatibility.

- Changes in groups are allowed any time after the first test attempt.

- Students are allowed to choose an individual option, but are strongly encouraged to work in groups.

\section{Leadership selection}

An effective leader can make the difference in achieving greater group cohesion, more inclusion and a higher quality of work. How should the group leader be selected? Democratic selection is frequently favoured, as we would then expect the nominated leader to enjoy support from the group. However, a difficulty is encountered where members of the group do not know each other very well and leadership is needed from the start in order to meet tight deadlines.

Selecting students with the relevant leadership personality characteristics may be problematic, particularly when dealing with very large numbers of students. Brown (1988), in a review of empirical investigations into personality characteristics of group leaders, did not find many reliable correlations because various studies gave different associations. However, they did report some indication that leaders may be slightly more self-confident, dominant, sociable, achievement orientated, experienced, intelligent, and taller and older than the other group members.

Rough-and-ready approaches are suggested by a common finding that an important characteristic of leaders is that they have a tendency to initiate activities in the group. Students with this type of characteristic can be easier to identify: for example, the lecturer can ask interested students to undertake a proactive activity, such as applying by email for the position of group leader, with a rationale as to why it would be useful to them personally.

\section{Group procedures}

It has been suggested that there are four critical stages for an effective group process, consisting of the rhyming stages: forming, storming, norming and performing (Tuckman, 1965; Bligh, 2000; Cameron, 2002). Adjourning was subsequently added as a fifth stage in 1977. Forming relates to the initial situation where members get to know each other and are trying to determine appropriate behaviour. Storming is the following stage, where there can be considerable conflict and strong status battles. The group's understanding of the task should be explored in this forming and storming time. At this point the group can move towards more cohesion or 
complete disintegration. Norming refers to the stage where norms have emerged within the group. The performing stage refers to the position where the group begins to work efficiently as the necessary roles within the group are adopted.

An alternative seven-stage model for phases in group development is provided by Johnson and Johnson (1987). It consists of:

- Setting up the group and providing information (defining and structuring procedures).

- The group getting to know each other while still dependent on the tutor for directions (sticking to procedures and getting acquainted).

- Recognising mutuality and building trust. At this stage, group members start to recognise their independence.

- Some features of rebellion. There may be resistance to some of the responsibilities accepted earlier.

- Ownership of goals and procedures. It becomes the members' group rather than the tutor's. The norms of the group are internalised.

- The group functioning in appropriate ways to achieve its goals: that is, performing maturely.

- Conclusion of the task and winding up of the group.

\section{How to speed up progress}

Groups may spend considerable time in inconclusive activity. They can spend long periods trying to arrange mutually convenient times for their next meeting and postponing decisions. Practical options to this problem include:

- Staff members adopting a more 'hands-on' approach, particularly in the early stages. By being present at meetings, tutors might intervene by providing suggestions and prompts designed to get the group moving, although tutors should beware of trying to exert too much influence. A common cause of paralysis is the absence of team members and it can be useful to suggest a practical option such as to record and circulate decisions reached in each meeting to all team members. This should be accompanied by the instruction that any responses or disagreements are sent to the group manager by a particular date. After that date, without any responses, it can be legitimately assumed that there is agreement with the decision.

- Clarifying stages to be completed in the task. A simple example of a five-stage project might be:

1. The group selects a manager and the group tutor is notified.

2. The group develops a project proposal and presents it to the group tutor.

The project is then carried out in three stages:

3. Research stage.

4. Production stage.

5. Presentation.

Competitive pressures can be introduced by giving advantages for groups that complete certain stages ahead of other groups. Using the above example for illustration, the group may be offered a 'first come, first served' choice of a limited selection of project topics that can only be made after selection of a group manager. Furthermore, if the groups are making presentations, these could be allocated in reverse order to the receipt of the groups' project proposals.

An alternative to the use of competitive pressures is the use of a directed process, such as groups being told to reach certain stages by particular times, on the pain of losing marks. 


\section{Assessment}

\subsection{Methods of assessment}

The advantages and disadvantages of different approaches to group assessment are discussed in Race (2000). The argument for using group work in assessment is that it will reward achievements that are not adequately recognised in individual forms of assessment (for example, in contributions to joint presentations, social skills in group membership and reflection on peer activity). Presentations of group work give good opportunities for the assessment of oral skills, which are particularly important for employability.

Oral assessment does, however, create problems in terms of the time taken up by requiring an audience (typically of students and staff) and assessment reliability (Adnett, 2000). The first of these problems might be addressed by making the critical review of peers' presentations also part of the assessment process. Students will learn more from the contributions of others if they feel motivated to engage critically with the content of what is being presented. The second problem may be addressed through sharing criteria for the oral assessment with the students in advance of the presentation (Davies, 2000).

A form of assessment, relevant for group work and with direct applicability to concepts of deeper learning, is the reflective log or report (see section 5.3 for further reading). There is no single convention about log structure. As with other written submissions, the criteria for assessment should be devised as appropriate to the aims of the work. Given the less common nature of this type of assessment and the variety of possible objectives, it is critical that the assessment criteria are made clear to students. Reflective logs can be used for purposes including:

- assessment of other group members by the use of a standardised peer assessment format;

- self-assessment, where students evaluate their own performance against targets;

- tutor assessment of the depth of understanding and involvement of the student (Habeshaw et al. (1993, p. 85) remind us that criteria can include 'originality, commitment, skills of observation, analysis and synthesis, sensitivity, self-knowledge etc.');

- providing a back-up to other assessment systems (that is, in cases of dispute or ambiguity, the $\log$ can be used as a supportive document).

\subsection{Peer- and self-assessment}

Peer- and self-assessment have substantial advantages (see section 5.4 for further reading) and these are summarised by Race (2001):

- Students are already self-assessing and peer assessing quite naturally.

- Tutor assessment is not sufficiently valid, reliable or transparent.

- Peer- and self-assessment deepen students' learning experiences.

- They let students into the assessment culture.

- They help students towards becoming autonomous learners.

- They help students develop skills relating to life-long learning. 
- They help students to gain much more feedback than would otherwise be possible.

- Some of the drudgery can be saved by peer assessment.

- Self-assessment gets students to reflect on their own work, and can open up productive student-tutor dialogues.

- Students' performance in traditional assessments is enhanced.

A number of appropriate peer- and self-assessment checklists are included in Jaques (2000). One of these lists concentrates on students' skills in organising their learning:

- Contribution to group discussion.

- Carries out instructions and degree of supervision needed.

- Works easily with others.

- Response to criticism.

- Polite with colleagues.

- Ability to organise own work.

- Ability to supervise others' work.

- Speed of recognising essentials.

- Adaptability to new situations.

- Efficiency at solving problems.

A mark of 1-5 is applied on a scale that goes from a very positive assessment of their colleagues' ability to a very negative assessment.

Instead of checklists completed by all students, we can opt for forms that are completed by the project group leaders. Elliott (2001) adopts this method in a group project for first-year business economics, with statements being made about the work of each group member.

The argument for self- and peer assessment is not one-sided. There are dangers of student bias that need to be allowed for. Typically, bias may arise from:

- reticence about providing negative information on fellow students;

- reluctance to cover a full spectrum of marks, with realistic maxima and minima;

- collusion that disadvantages some individuals;

- reluctance to fail a student.

Design options to counter such bias include:

- initial discussion, input and commitment by students to assessment programme;

- checking uniformity of student opinion (e.g. individual questionnaires);

- observing anonymity in assessment (e.g. questionnaires completed in class);

- a clear procedure for arbitration on disputed assessments;

- a procedure for investigation of student participation (e.g. vivas, log books and exams).

\subsection{Allocating marks in group assessments}

An elementary marking scheme, often appropriate for small-scale group work in a controlled environment, has the mark for the group output being allocated equally. Where we wish to encourage and reward task- or process-related activities, individual members can receive different marks. For example, for additive and conjunctive tasks each member's individual work might be identified and graded. For any format of task, individuals may also be graded on various performance criteria. Where there is an overall group mark and these individual grades, we have the choice of adopting an additive or multiplicative model. 
With an additive system, the marks for the individuals' performance are added to the group mark. For example, a group report may be marked out of 80 per cent and each individual's contribution out of 20 per cent is then added. Alternatively, the individual's performance may be marked on the basis of penalty points. A group report can be marked out of 100 per cent and the individual's contribution results in deductions starting at 0 per cent for wholly exceptional, -5 per cent for very good, etc. With a multiplicative model, the mark for the group task is adjusted by a weighting given to the individual assessment. Numerous variations are possible, and one way of avoiding the 'grade inflation' endemic with such a system is that the average student in the individual assessment gets the group mark. Those better than average get a percentage above the group mark, and those below average get a percentage below the group mark.

To emphasise the importance of the group work, it is usual to weight it more heavily than the individual mark: for example, 70:30. A group mark can be awarded that the group must then divide amongst themselves. If the scheme works correctly, they will divide the mark between themselves according to their in-depth knowledge of their relative contributions. Back-up procedures in case of non-agreement need to be available.

Consensus over performance assessment is not always achieved and it is important to have agreed arbitration procedures. A University of Nottingham case study in the LTSN Engineering Work Group Report (2002) illustrates the type of flexibility needed. Student groups were asked to reflect on each member's contribution and indicate any mark redistribution they felt appropriate. However, 'if agreement could not be reached then an individual (confidential) peer assessment form was sent to each group member and a peer assessment adjudication constructed by the module staff.' 


\section{Where next?}

\subsection{Group structure}

Group structure can have profound effects on what students achieve in terms of both group learning and task accomplishment. Jaques (2000, chapter 6) provides information on a wide range of alternative structures, with possible variations on each. It ranges from the minimal-size Buzz groups, where students turn to their neighbours for discussion (often used in lectures to provide a break), to other forms of direct communication such as 'Snowball', 'Fishbowl', 'Crossover', 'Delphi' and 'Nominal' groups.

\subsection{Feedback}

Twenty-one general hints regarding the giving of feedback to enhance learning are contained in Brown et al. (1996, pp. 30-3).

\subsection{Reflective logs}

Economics students will need guidance on how to approach their reflective logs. This is important both to ensure that they utilise the deeper learning opportunities of the exercise and to facilitate assessment. Race (2000, pp. 79-81) provides a useful starting point, providing ten general tips on 'helping learners to write reflections on group learning'.

\subsection{Assessment}

See 'Alternative forms of formative and summative assessment' in the Economics LTSN Economics Handbook for top tips on self- and peer assessment and considerations to apply in a self-assessment form

See Race (2001) for a useful briefing on self-, peer and group assessment. There is a particularly helpful illustration in the appendix of the processes that can be applied for students to develop ownership of the peer assessment criteria.

See also Brown et al. (1996), Brown (2001) and Michaelson (2000).

\subsection{Group selection}

The Belbin approach is useful in practice, as it relates to measurement and identification of relevant behaviour. There is considerable evidence that group work will benefit by selecting group members with regard to their preferred Belbin roles (see Cameron, 2002). A very practical activity guide to Belbin is given in O'Sullivan et al. (1996, pp. 59-66). 
The alternative options of psychometric testing measure personality and may offer a more sophisticated insight or be longer lasting than behaviour. However, they are generally agreed to be more difficult to relate to relevant group behaviour. The very popular Myers Briggs Type Indication is available online.

Variations between the group requirements for complex and simple tasks is a relevant issue in group selection. Useful considerations of group task congruence are provided by Clark et al. (2001).

\subsection{Virtual Learning Environments}

Collaborative learning can be assisted in many practical ways by Virtual Learning Environments (VLEs) such as Blackboard and WebCT. VLEs can also have beneficial effects on the dynamics of group communication. Manning and Riordan (2000) provide an interesting outline of some of the literature on and benefits of groupware to support collaborative learning, including a macroeconomic case study. O'Leary and Cai (2003) in a SOLE Case Study Series on Economics provide an assessment of two year 1 economics modules that used Blackboard and WebCT, one of these case studies focusing on collaborative learning in groups.

\subsection{Economics test questions applicable for group work}

Samples of quiz questions for group work, when teaching introductory economics, are located in the appendix to Moore (1998). The article provides useful detail on how the task is structured.

\subsection{General}

Baron, R. S., Kerr, N. L. and Miller, N. (1992) Group Process, Group Decision, Group Action, Open University Press, Buckingham.

Fiechtner, S. B. and Davis, E. A. (1992) 'Why some groups fail: a survey of students' experiences with learning groups', in A. S. Goodsell, M. R. Maher and V. Tinto (eds), Collaborative Learning: A Sourcebook for Higher Education, National Center on Postsecondary Teaching, Learning and Assessment, Syracuse University. 


\section{References}

Adnett, N. (2000) 'Introducing peer group assessment in an undergraduate economics programme', in P. Davies, S. Hodkinson and P. Reynolds (eds), Innovative Approaches to Learning and Teaching in Economics and Business Higher Education, Trentham Books, Stoke-on-Trent.

Bales, R. and Borgatta, E. (1955) 'Size of group as a factor in the interaction profile', in P. Hare, E. Borgatta and R. Bales (eds), Small Groups: Studies in Social Interaction, Alfred A. Knopf, New York.

Bartlett, R. (1998) 'Making cooperative learning work in economics classes', in W. Becker and M. Watts (eds), Teaching Economics to Undergraduates: Alternatives to Chalk and Talk, Edward Elgar, Cheltenham.

Becker, W. E. and Watts, M. (eds) (1998) Teaching Economics to Undergraduates: Alternatives to Chalk and Talk, Edward Elgar, Cheltenham.

Belbin, R. M. (1981) Management Teams, Heinemann, London.

Bligh, D. (2000) What's the Point in Discussion?, Exeter: Intellect Books.

Brown, G. (2001) Assessment: A Guide for Lecturers, Generic Assessment Series, No. 3, LTSN Generic Centre, York.

Brown, R. (1988) Group Processes: Dynamics within and between Groups, Blackwell, Oxford.

Brown, S., Race, P. and Smith, B. (1996) 500 Tips on Assessment, London: Kogan Page.

Cameron, S. (2002) Business Student's Handbook: Learning Skills for Study and Employment, Prentice Hall, Harlow.

Cardiff University (2001) 'Guidance on group work', online at http://www.cardiff.ac.uk/schoolsanddivisions/divisions/learning/guidance/group.html

Charkins, R. J., O’Toole, D. M. and Wetzel, J. N. (1985) 'Linking teacher and student learning styles with student achievement and attitudes', Journal of Economic Education, vol. 16, spring, pp. 111-20.

Clark, M. A., Blancero D., Luce, C. and Marron, G. (2001) 'Teaching work group-task congruence: the fit for performance exercise', Journal of Management Education, vol. 25, no. 5 , pp. 531-52.

Coffield, F., Moseley, D., Hall, E. and Ecclestone, K. (2004) Learning Styles and Pedagogy in Post-16 Learning: A Systematic and Critical Review, Learning and Skills Council, London.

Cooper, J., Prescott, S., Cook, L., Smith, L., Mueck, R. and Cuseo, J. (1990) Cooperative Learning and College Instruction: Effective Use of Student Learning Teams, California State University Foundation, Long Beach, CA.

Davies, P. (2000) 'Assessment criteria for learning and teaching economics', in P. Davies, S. Hodkinson and P. Reynolds (eds), Innovative Approaches to Learning and Teaching in Economics and Business Higher Education, Trentham Books, Stoke-on-Trent. 
Economics LTSN (2003) '2003 Economics LTSN survey of economics lecturers', online at http://www.economicsnetwork.ac.uk/projects/lec_survey2003.htm, Economics LTSN, University of Bristol, Bristol.

Elliott, C. (2001) 'Case study: group project assessment in first year business economics', online at http://www.economicsnetwork.ac.uk/showcase/elliott_assess.htm

Festinger, L. (1954) 'A theory of social comparison processes', Human Relations, vol. 7, pp. 117-40.

Gibbs, G. (1994) Learning in Teams: A Student's Guide, Oxford Centre for Staff Development, Oxford Brookes University, Oxford.

Habeshaw, S., Gibbs, G. and Habeshaw, T. (1993) 53 Interesting Ways to Assess Your Students, The Cromwell Press, Melksham.

Hendry, G. D., Frommer, M. and Walker, R. A. (1999) 'Constructivism and problem-based learning', Journal of Further and Higher Education, vol. 23, no. 3, pp. 359-71.

Holt, J. H. (1987) 'The social labouring effect: a study of the effect of social identity on group productivity in real and notional groups using Ringelmann's methods', unpublished manuscript, University of Kent.

Jaques, D. (2000) Learning in Groups, 3rd edn, Kogan Page, London.

Johnson, D. W. and Johnson, F. P. (1987) Joining Together: Group Theory and Group Skills, Prentice Hall, Englewood Cliffs.

Johnson, D. W., Johnson, R. T. and Smith, K. A. (1998) Active Learning: Cooperation in the College Classroom, Interaction Book Co., Edina, MN.

Johnson, D.W, Maruyama, G., Johnson, R., Nelson, D. and Skon, L. (1981) 'Effects of cooperative, competitive, and individualistic goal structures on achievement: a meta-analysis', Psychological Bulletin, vol. 89, pp. 47-62.

Johnston, C. G., James, R. H., Lye, J. L. and McDonald, I. M. (2000) 'An evaluation of collaborative problem solving for learning economics', Journal of Economic Education, winter, pp. 13-29.

Kolb, D. (1984) Experiential Learning, Prentice Hall, Englewood Cliffs, NJ and Harlow.

Lage, M., Platt, G. and Treglia, M. (2000) 'Inverting the classroom: a gateway to creating an inclusive learning environment', Journal of Economic Education, vol. 31, winter, pp. 30-43.

LTSN Engineering (2002) LTSN Engineering Working Group Report: Assessment of Individuals in Teams, online at http://www.ltsneng.ac.uk/downloads/resources/ Bobharris_webfinal2.pdf, LTSN Engineering, Loughborough University, Loughborough.

Manning, L. M. and Riordan, C. A. (2000) 'Using groupware software to support collaborative learning in economics', Journal of Economic Education, summer, pp. 244-52.

Michaelson, R. (2000) 'Assessing group work', LTSN-BEST Briefing Paper, online at http://www.business.heacademy.ac.uk/publications/misc/briefing/groupwork

Morgan, P. (2002) 'Supporting staff to support students: the application of a performance management framework to reduce group working problems', online at http://www.business.heacademy.ac.uk/resources/reflect/conf/2002/morgan.

Moore, R. L. (1998) 'Teaching introductory economics with a collaborative learning lab component', Journal of Economic Education, fall, pp. 321-9. 
O’Leary, R. and Cai, C. (2003) 'SOLE Case Study Series, Economics', online at http://sole.ilrt.bris.ac.uk,

O’Sullivan, T., Rice, J., Rogerson, S. and Saunders, C. (1996) Successful Group Work, Kogan Page, London, in association with De Montfort University.

QAA (2000), 'Subject benchmark statement Economics', online at http://www.qaa.ac.uk/crntwork/benchmark/economics.html, Quality Assurance Agency, Gloucester.

Race, P. (2000) 500 Tips on Group Learning, Kogan Page, London.

Race, P. (2001) A Briefing on Self, Peer and Group Assessment, Generic Assessment Series, No. 9, LTSN Generic Centre, York

Ruel, G. and Bastiaans, N. (2003) 'Free-riding and team performance in project education', International Journal of Management Education, vol. 3, no. 1, pp. 26-37.

Skok, W. (2003) 'A hitch-hiker's guide to learning in higher education', Best Practice, vol. 4, no. 1 , pp. 10-12.

Sloman, J. (2002) Case study: 'the international trade game', online at http://www.economicsnetwork.ac.uk/showcase/sloman_game.htm

Steiner, I. D. (1972) Group Process and Productivity, Academic Press, New York.

Tuckman, B. W. (1965) 'Developmental sequences in small groups', Psychological Bulletin, vol. 63 , no. 6, pp. 384-99.

Watkins, R. and Daly, V. (2003) 'Issues raised by an approach to group work for large numbers', BEST Conference, Brighton, 9-11 April. 
The Handbook for Economics Lecturers 